\title{
Pain management with nature herbs
}

\author{
Hameed Mohamed Rafeek* \\ Consultant in Alternative Medicine, Naturopathic Iridologist \& Specialist in Pain Management, Sri Lanka
}

*Corresponding author: Hameed Mohamed Rafeek, Consultant in Alternative, Medicine, Naturopathic Iridologist \& Specialist in Pain Management, Advisor to state ministry of health and indigenous medicine, Sri Lanka.
Received Date: December 12, 2019

Published Date: January 07, 2020

\section{Opinion}

Today in the world people are looking for nature medicines for pain relief big why, when where, what all these question arises because of chemical formula medicines, it gives long period of chronic pain and thus application of pain drugs, oil or cream thus it can affect the body condition internal organ, it gives a lot of side effects therefore the patients are looking for without high dosage medicines except surgery. Based on complementary medicine there are number of herbs available to reduce the pain, American foundation and my research relieving the pain management particularly St John's sceitica, arthritis neuropathic pain not only that vellarian herbs can be used for muscle cramps. Sometimes we can use it for common treatment, we are neuropathy treatments, vitamin canine pepper, warm bath, essential oil, meditation such as for base of complementary medicine sight. Some people with neuropathic pain familiar over the counter aspirin, ibubrufen while these drugs may help with the occupational pain, but they are not strong for the nervous pain, thus long process treatment cannot be taken with these medicines as it will not be effective. Some herbs such as ginseng willow bark tumeric, cloves, these are good for pain relief as well if you have a backache, any other type of pain. Under the category of Alternative medicine practice with acupuncture except surgery. However, willow bark comes with its own risk of effect such as stomach aches, reduce kidney functioning. Should only be used by adults. If you are taking aspirin for antiflamatory drugs, should avoid willow bark. You can use tumeric for indigestion, ulcers and suracis, cancers and stomach upsets. Cloves often used for spicing up and rice dishes. Grown cloves are used for tasty purposes and peas. cloves are available in oil form to relieve pain.

I would like to mention here, a patient who has a heavy heachache called migraine the best herbs to use to treat is feverfew and butternut over the counter pain. suggestion few essential oil for helpful for pain receive over medication lavender essential oil and remembered essential oil, peppermint, eccalps essential oil, some evidence shows that these are helpful and for those who feel reluctant to sleep and have anxiety, and pain in muscles in my clinical experience peppermint oil the best to suggest antiflammatory antimicrobial and pain relievers.

\section{Conclusion}

Lastly, pain relief can be treated by natural herbs.

\section{Acknowledgement}

None.

\section{Conflicts of Interest}

No conflicts of interest. 